\title{
Chest X-Ray Image Analysis
}

\section{A Vision of Logic Programming}

\author{
João Neves ${ }^{1}$, Ricardo Faria ${ }^{2}$, Victor Alves ${ }^{2}$, Filipa Ferraz ${ }^{2}$, \\ Henrique Vicente ${ }^{2,3}$, and José Neves ${ }^{2(凶)}$ \\ ${ }^{1}$ Mediclinic Arabian Ranches, PO Box 282602, Dubai, United Arab Emirates \\ joaocpneves@gmail.com \\ 2 Centro Algoritmi, Universidade do Minho, Braga, Portugal \\ ricardo.mof@hotmail.com, \\ \{valves, jneves\}@di.uminho.pt, filipatferraz@gmail.com \\ ${ }^{3}$ Departamento de Química, Escola de Ciências e Tecnologia, \\ Universidade de Évora, Évora, Portugal \\ hvicente@uevora.pt
}

\begin{abstract}
Most cardiovascular diseases can be prevented by addressing behavioral risk factors such as tobacco use, unhealthy diet and obesity, physical inactivity and harmful use of alcohol using strategies of the entire population. People with cardiovascular disease or high cardiovascular risk (due to the presence of one or more risk factors, such as hypertension, diabetes, hyperlipidemia or already established disease) need early detection and management using counseling and medication as appropriate. Now a leading cause of death. In fact, it reveals the centrality of prevention and how important it is to be aware of these situations. Thus, this paper will focus on the development of a decision support system to prevent these events to happen, centered on a structure based on Logic Programming for Representation and Knowledge Reasoning, complemented with a case-based approach to computation.
\end{abstract}

Keywords: Chest X-Ray images - Knowledge representation and reasoning Logic programming $\cdot$ Case-based reasoning $\cdot$ Decision support systems 